\title{
Influence of Leaf Wetness Duration and Temperature on Infection of Grape Leaves by Elsinoë ampelina under Controlled and Vineyard Conditions
}

\author{
Odile Carisse, ${ }^{1, \dagger}$ Audrey Levasseur, ${ }^{1}$ and Caroline Provost $^{2}$ \\ ${ }^{1}$ Saint-Jean-sur-Richelieu Research and Development Centre, Agriculture and Agri-Food Canada, Saint-Jean-sur-Richelieu, QC, \\ J3B 3E6, Canada \\ ${ }^{2}$ Centre de recherche agroalimentaire de Mirabel, Mirabel, QC, J7N 2X8, Canada
}

\begin{abstract}
On susceptible varieties, indirect damage to vines infected by Elsinö̈ ampelina range from reduced vigor to complete defoliation while, on berries, damage ranges from reduced quality to complete yield loss. Limited knowledge about the relationship between weather conditions and infection makes anthracnose management difficult and favors routine application of fungicides. The influence of leaf wetness duration and temperature on infection of grape leaves by E. ampelina was studied under both controlled and vineyard conditions. For the controlled conditions experiments, the five youngest leaves of potted vines (Vidal) were inoculated with a conidia suspension and exposed to combinations of six leaf wetness durations (from 0 to $24 \mathrm{~h}$ ) and six constant temperatures (from 5 to $30^{\circ} \mathrm{C}$ ). A week after each preset infection period, the percent leaf area diseased (PLAD) was assessed. At $5^{\circ} \mathrm{C}$, regardless of the leaf wetness duration, no disease developed. At 10 and at 15 to $30^{\circ} \mathrm{C}$, the minimum leaf wetness durations were 4 and $6 \mathrm{~h}$, respectively. Above

lower rate from 12 to $24 \mathrm{~h}$. The optimal temperature for infection was $25^{\circ} \mathrm{C}$. Relative infection was modeled as a function of both temperature and wetness duration using a Richards model $\left(R^{2}=0.93\right)$. The predictive capacity of the model was evaluated with data collected in experimental vineyard plots exposed to natural wetness durations or artificial wetness durations created using sprinklers. In total, 264 vineyard infection events were used to validate the controlled experiments model. There was a linear relationship between the risk of infection estimated with the model and the observed severity of anthracnose $\left(R^{2}=90\right)$; however, the model underestimated disease severity. A risk chart was constructed using the model corrected for vineyard observations and three levels of risk, with light, moderate, and severe risks corresponding to $\leq 5,>5 \%$ to $\leq 25$, and $>25 \%$ leaf area diseased, respectively. Overall, $93.9 \%$ of 132 independent observations were correctly classified, with 100, 29.4, and $9.4 \%$ of the light, moderate, and severe risks, respectively.
\end{abstract} the minimum wetness duration, at temperatures from 10 to $30^{\circ} \mathrm{C}$, PLAD increased linearly, with increasing leaf wetness up to $12 \mathrm{~h}$, and then at a
Keywords: climate/weather effects, epidemiology, fruit, fungi, small fruits
Grape anthracnose, caused by the ascomycetes fungus Elsinö ampelina (Shear), is a disease originating from Europe that has spread to all continents where conditions are favorable for its establishment (Barros et al. 2015; Brook 1992; Du Plessis 1940; Magarey et al. 1993; Suhag and Grover 1977; Thind et al. 2001). Depending on the severity of the disease, grapevines infected by E. ampelina will have slowed development and delayed berry ripening, which could be crucial under northern climates. Infected vines produce significantly lower yield due to inflorescence, twig mortalities, and berry rot, and are less resistant to winter conditions. Severely infected vines can be partially or completely defoliated, resulting in losses over several years and increased cost of production and replanting (Carisse and MorissetteThomas 2013). On susceptible grape varieties, yield and vine losses attributable to anthracnose and the cost of frequent fungicide applications make cost-effective production difficult during warm and humid seasons (Hopkins and Harris 2000). Considering the devastating nature of anthracnose and the cost of replanting vineyards, disease management is mostly achieved with fungicides applied from budbreak to veraison at 7- to 14-day intervals (Carisse et al. 2009).

The knowledge about grape anthracnose comes mainly from studies carried out in Uruguay, India, and Australia (Brook 1973;

${ }^{\dagger}$ Corresponding author: O. Carisse; odile.carisse@ canada.ca

Funding: This work was financially supported by Agriculture and Agri-Food Canada and component 4 of the Prime-Vert program (2013-2018) from the Ministère de l'Agriculture, des Pêcheries et de l'Alimentation (MAPAQ) through the Stratégie phytosanitaire québécoise en agriculture 2011-2021.

The author(s) declare no conflict of interest.

Accepted for publication 21 May 2020.

(c) 2020 Her Majesty The Queen in Right of Canada as represented by the Minister of Agriculture and Agri-Food.
Magarey et al. 1993; Suhag and Grover 1972). However, as the grapevine and table grape industry has expanded in different parts of the world, more knowledge about grape anthracnose is becoming available (Barros et al. 2015; Carisse and Lefebvre 2011a,b; Carisse and Morissette-Thomas 2013). In eastern Canada, the sensitivity of grape varieties cultivated, the production of primary inoculum in the spring as a function of temperature, and the influence of host and weather on the defoliation of grapevines by E. ampelina was studied (Carisse and Lefebvre 2011a,b; Carisse and MorissetteThomas 2013). However, knowledge about the development of anthracnose has not yet translated into a control strategy.

E. ampelina overwinters as sclerotia in cankers on woody stems, shoots, and pruning left on the soil, and in infected berries (Carisse and Lefebvre 2011a; Shear 1929; Suhag and Grover 1972). In the spring, these sclerotia germinate and produce conidia after a period of at least $24 \mathrm{~h}$ of wetting at a temperature above $2^{\circ} \mathrm{C}$. Conidia dispersed by the rain infect the green organs of the vine (Mirica 1988). These primary infections are localized not only on the leaves but also on the stems and clusters. The fungus then forms acervuli, where conidia responsible for secondary infections are produced (Mirica 1988). Secondary infections cause most of the damage. Depending on the temperature, conidia require more or less wetting time to germinate, between 1.5 and $10 \mathrm{~h}$ of wetness. The higher the temperature, the shorter the wet period required (Magarey et al 1993). It is important to note that these infections are present mostly on growing tissues. The incubation period varies depending on the temperature, between 4 and 13 days. In summary, the optimal temperature for the development of anthracnose is 24 to $26^{\circ} \mathrm{C}$ but rain and the presence of free water are the most limiting factors for infection (Mirica 1988). At the end of the summer, sclerotia develop in the edges of the stem cankers.

On young leaves, symptoms of anthracnose are characterized by small (1 to $4 \mathrm{~mm}$ ), moist, brown to chocolate-brown lesions. These lesions progress and become circular or angular, with a center that is rather gray and dry, surrounded by a dark-brown ring. These 
lesions appear on the blade but especially near the veins, where they cause complete wilting of the leaf (Carisse and Lefebvre 2011b; Carisse and Morissette-Thomas 2013). The lesions remain isolated or confluent and may cover important areas of the limbus. They sometimes present a chlorotic halo that is more or less marked. On young leaves, when many lesions develop along the veins, leaf mortalities can occur (Carisse and Morissette-Thomas 2013). On stems, the lesions are small, round or angular, and are surrounded by a darker ring that changes from brown-purple to black-purple. The centers of these lesions form a well inside the stem which, over time, increases the susceptibility of the branches to breaks (Carisse and Lefebvre 2011b). The lesions on bunches are similar to those found on stems; they are surrounded by a dark-brown ring, the center of which changes from purple to gray. These lesions cause cracking of the berries. All of this damage of course leads to an inevitable loss of vigor of the plant and a loss of production.

Given the climate of eastern Canada, grapevine varieties must be chosen for their organoleptic qualities but also for their hardiness, vegetative period, and early maturity (Plocher and Parke 2001). Nonhardy grape plants must be protected during the winter, which implies additional costs and risks of losses due to winter frost. Several winemakers have turned to grape varieties adapted to cold climates such as Vandal-Cliche, Marquette, or Frontenac. Unfortunately, many of these varieties are susceptible to anthracnose (Carisse and Lefebvre 2011b). Because the epidemiology of anthracnose is still not fully understood, particularly under the climatic conditions of Quebec, it remains difficult for grapevine growers to define a good management strategy. Hence, our medium-term objective was to develop a forecasting system based on the influence of weather on the main processes of the E. ampelina life cycle (Carisse and Lefebvre 2011a). The specific objectives of this study were to (i) examine the influence of leaf wetness duration and temperature under controlled conditions and to model the response of relative disease severity (RSEV) to leaf wetness and temperature, (ii) evaluate the capacity of the model to reliably predict disease risk using vineyard data, and (iii) construct a risk chart that can be used to estimate the potential risk of anthracnose based on leaf wetness duration and temperature.

\section{Materials and Methods}

Influence of duration of leaf wetness and temperature under controlled conditions. Inoculum production. Isolates of E. ampelina obtained from naturally infected grape leaves collected in 2012 and 2013 at the Agriculture and Agri-Food Canada experimental farm in Frelighsburg, Quebec, and at a commercial vineyard located at Saint-Wenceslas, Quebec, were used for inoculation. The isolates were stored as mycelium in sterile soil at $4^{\circ} \mathrm{C}$. The pathogen was subjected to host passages on grape leaves (cultivar Vidal), and lesions were subsequently maintained at room temperature on grapevine leaf agar (VLA). To prepare the VLA, a grape leaf infusion was made by adding $30 \mathrm{~g}$ of grape leaves to $800 \mathrm{ml}$ of boiling water. Immediately after the leaves were dropped into the boiling water, the hot plate was turned off and the leaves were left to simmer for $20 \mathrm{~min}$. This infusion was filtered through two layers of cheesecloth, and the solution was adjusted to 1 liter by adding distilled water. To produce 1 liter of culture medium, $19.5 \mathrm{~g}$ of potato dextrose agar, $12.5 \mathrm{~g}$ of agar, $1 \mathrm{~g}$ of $\mathrm{CaCO}_{3}$, and $100 \mathrm{mg}$ of Novobiocin were added (Sigma Chemical Co., St. Louis, MO, U.S.A.). Because E. ampelina does not produce large amounts of conidia on artificial media, sterile grape leaves (Vidal) were placed on the surface of petri dishes containing VLA, with one leaf per dish. A mycelial slurry was made by homogenizing 4- to 7-day-old cultures obtained from the lesions maintained on VLA and sterile water. These grape leaves were then drop- inoculated with the mycelial slurry at a rate of 100 to $150 \mu l$ per dish. The dishes were then sealed with parafilm and maintained at room temperature $\left(20\right.$ to $24^{\circ} \mathrm{C}$ ) for 4 to 8 days. On the day of inoculation, a conidial suspension was prepared in distilled water and adjusted to $1 \times 10^{6}$ conidia/ml with a hemocytometer. To determine the percent germination of conidia, five drops of $8 \mu$ l each of the conidial suspension were placed on the surface of a dish containing $10 \mathrm{ml}$ of water agar (15 $\mathrm{g}$ of agar per liter). The dish was then maintained at room temperature $\left(20\right.$ to $\left.24^{\circ} \mathrm{C}\right)$ for $20 \mathrm{~h}$. Percent germination was assessed under an inverse microscope, and a conidium was considered as germinated when the germination tube was at least twice the length of the conidium.

Plant production, inoculation, and disease assessment. Dormant bare-rooted grapevine plants (Vidal) were transplanted into 2-liter pots filled with a general-purpose peat-based growing medium (PRO-MIX BX) and were placed in a greenhouse maintained at $20^{\circ} \mathrm{C}$ during the day and $18^{\circ} \mathrm{C}$ during the night, with a 16-h photoperiod. Fertilizer was applied at the time of transplanting as 10-52-10 $\left(\mathrm{N}-\mathrm{P}_{2} \mathrm{O}_{5}-\mathrm{K}_{2} \mathrm{O}\right)$ at at a rate of $2 \mathrm{~g} /$ liter. The plants were pruned down to two shoots and kept in the greenhouse until each shoot had at least five fully expanded leaves (approximately 4 weeks). On the day of inoculation, the five youngest expanded leaves of each shoot were tagged. Both adaxial and abaxial leaf surfaces of each tagged leaf were inoculated with the E. ampelina conidia suspension as a uniform layer of fine droplets using an airbrush (compressor model TC-63tc by Sparmax and airbrush model VL by Paasche Airbrush Co., Chicago, IL, U.S.A.) operated at $150 \mathrm{kPa}$.

Inoculated plants, except those exposed to $0 \mathrm{~h}$ of wetness, were covered with clear plastic bags with the inner side sprayed with water to create leaf wetness, and placed immediately in a growth chamber (model E15; Conviron Co., Manitoba, Canada) at a constant temperature of $5,10,15,20,25$, or $30^{\circ} \mathrm{C}$. After $2,4,6,12$, or $24 \mathrm{~h}$ of exposure to wetness, three plants were transferred to a greenhouse maintained at $20^{\circ} \mathrm{C}$ during the day and $18^{\circ} \mathrm{C}$ during the night with a 16-h photoperiod. When plants were introduced into the greenhouse, the plastic bags were removed, and the plants were exposed to a smooth airflow supplied by an electric fan until the leaf surface was dry (15 min). Plants exposed to $0 \mathrm{~h}$ of wetness duration were dried immediately after inoculation. Disease severity was assessed 9 days after inoculation as percent leaf area diseased (PLAD) using the software ASSES (Assess 2.0: Image Analysis Software for Plant Disease Quantification, American Phytopathological Society, St. Paul, MN, U.S.A.). This procedure was repeated three times, each time at a different temperature. The experimental design was a split plot, with temperature and duration of leaf wetness as main units and subunits, respectively. The entire experiment was conducted three times (assays). The order in which plants were inoculated, temperature selected, and distribution of plants in the growth chambers were randomized.

Data analysis and model development. Because temperatures were tested over time and with different inoculum suspensions (temperature and inoculum effects were confounded), homogeneity of variance between the three assays was tested to determine whether the percent conidia germination of the inoculum varied significantly among inoculations. Averaged values of disease severity over the 30 leaves (5 leaves $\times$ two shoots $\times$ three plants) per temperaturewetness combination were expressed as relative values (RSEV) by dividing each value (mean over 30 leaves) by the maximum value observed within each assay so that the data ranged from 0 to 1 . Based on observations of RSEV as a function of both temperature and duration of leaf wetness for each temperature tested, the Richards model (equation 1) was selected to model the data. The Richards model was fitted to the data as follows:

$$
R D S=A *\left[1-\exp ^{-r w}\right]^{\frac{1}{(1-m)}}
$$

where $R D S$ is the RSEV, $A$ is the asymptote (maximum RSEV), $r$ is the rate of disease progress, $w$ is the duration of leaf wetness (h), and $m$ is a shape parameter. The shape parameter $m$ can range from 0 to infinity. The surface response model was developed following four distinct steps (Carisse and Kushalappa 1990). First, the asymptote was expressed as a function of temperature using a second-order polynomial model (equation 2) as:

$$
A=\beta_{0}+\beta_{1} T+\beta_{2} T^{2}
$$

where $A$ is the maximum RSEV observed, $\beta$ are the regression coefficients, and $T$ is the temperature $\left({ }^{\circ} \mathrm{C}\right)$. The objective of the second step was to obtain predicted values for $m$ and $r$ for each of the 
temperatures tested. The Richards model (equation 1) was fitted to the data separately for each temperature and for each assay (six temperatures $\times$ three assays) using the predicted values of $A$ from equation 2. To estimate the value of the parameter $m$, partial derivatives equations were obtained and the Marquardt iterative method of the nonlinear regression (NLIN) procedure in SAS was used. The final value of $m$ was selected as the mean of the 18 values obtained from fitting equation 1 with the predicted values of $A$ (equation 2) separately to each temperature and each assay. The third step objective was to model the values of $r$ obtained from fitting equation 1 with $A$ expressed as a function of temperature (equation 2 ) and the value of $m$ selected from step two. Model fitting was conducted separately to the data from each temperature and each assay. Based on the shape of $r$ value response to temperature, a three-parameter lognormal model was selected and fitted to the $r$ values as:

$$
r=\frac{a}{T} \exp \left[-0.5\left(\frac{\ln \left(T / x_{0}\right)}{b}\right)^{2}\right]
$$

where $r$ is the rate parameters estimated from fitting the Richards model, $T$ is the temperature $\left({ }^{\circ} \mathrm{C}\right), a$ is a scale parameter, $b$ is a shape parameter, and $x_{0}$ is a location parameter that defines the inflection point at which the distribution of $r$ begins. To estimate the value of the parameter $r$, partial derivatives equations were obtained and the Marquardt iterative method of the NLIN procedure in SAS was used The final step consisted of integrating the estimated values of the asymptote $(A)$, the selected value of $m$, and the estimated value of the rate parameter $(r)$ into equation 1 to obtain the predicted $R D S$ as a function of both temperature $(T)$ and duration of leaf wetness $(w)$. The final model was evaluated by performing a simple regression analysis between the predicted values and the actual observations as paired observations. This regression was analyzed by testing whether the intercept was significantly different from 0 , whether the slope was significantly different from 1 , and whether the appropriate $F$ value was significant. Also, the concordance correlation coefficient (CCC) was used as a measure of the final model accuracy (Madden et al. 2007). The CCC was calculated as $r \times \mathrm{Cb}$, where $r$ is the Pearson product-moment correlation between observed and predicted RSEV and $\mathrm{Cb}$ is a bias coefficient. The bias coefficient is the deviation of the best-fitting line from the concordance line (perfect agreement between observed and predicted RSEV), which is a straight line with an intercept of 0 and a slope of 1 (Madden et al. 2007). Statistical analyses, including modeling procedures, were done with the statistical analysis system (version 9.4; SAS Institute Inc., Cary, NC, U.S.A.).

Validation of the infection model and development of a risk chart. Description of experimental vineyards and weather data collection. Data were collected in 2006, 2007, and 2008 at the Agriculture and Agri-Food Canada experimental farm located in Frelighsburg, Quebec, Canada (latitude $45^{\circ} 03^{\prime} 12^{\prime \prime} \mathrm{N}$, longitude $72^{\circ} 51^{\prime} 42^{\prime \prime}$ W) in a vineyard planted in 2000 with the grape varieties VandalCliche and Vidal, which are highly and moderately susceptible to anthracnose, respectively (Carisse and Lefebvre 2011b). The first experimental vineyard measured 30 by $30 \mathrm{~m}$ and was planted with the grape variety Vidal, with rows spaced $3.0 \mathrm{~m}$ apart and, within rows, the vines spaced $0.9 \mathrm{~m}$ apart. The second experimental vineyard measured 20 by $36 \mathrm{~m}$ and was planted with the grape variety Vandal-Cliche, with the rows spaced $2.0 \mathrm{~m}$ apart and, within rows, the vines spaced $1.2 \mathrm{~m}$ apart. During the course of the experiment, insecticides were applied when required, mainly to control flea beetle (Altica chalybea). Fungicides were applied only for downy mildew (Plasmopara viticola) using metalaxyl (Ridomil 2E; Novartis Crop Protection, Greensboro, NC, U.S.A.) at a rate of 2.33 liters/ha. Other cultural practices were applied in accordance with the standard practices.

The vineyard planted with the grape variety Vandal-Cliche was split into two sections. In one section, wetness was caused by natural weather conditions whereas, in the other section, sprinklers were used to create different durations of leaf wetness. In addition to natural rain, at least once weekly, an infection event was created, and the duration of artificial wetness was chosen considering forecast temperature and rain so that a range of leaf wetness ( 2 to $24 \mathrm{~h}$ ) at different temperatures was obtained. In the vineyard planted with the variety Vidal, wetness was due to rain and dew (no artificial rain). Weather data were obtained from automatic weather stations (CR21X; Campbell Scientific Inc., Edmonton, AB, Canada) placed in the center of each section of both experimental vineyards. Air temperature, relative humidity, rainfall, and leaf wetness data were monitored every $15 \mathrm{~min}$, and hourly averages or totals were used in the analyses. Leaf wetness was monitored using two electrical grid leaf wetness sensors (model 237-L) installed at an angle of $45^{\circ}$ within the middle and top portion of the grapevine canopy. Temperature and relative humidity were monitored at a height of $1.5 \mathrm{~m}$ using a Vaisala sensor (model HMP45C; Campbell Scientific Inc.) located in a white shelter. Rainfall was recorded with a tipping bucket rain gauge (Geneq, Montreal, QC, Canada) at a height of $50 \mathrm{~cm}$ above the ground.

Disease assessments and model validation. Starting at vine growth stage 11 (first expanded leaves on the $\mathrm{BBCH}$ scale), 10 vines per vineyard section were randomly selected and tagged, and each leaf present on two shoots per selected vine was assigned a unique number for tracking over time. At each assessment, new leaves, proportion of leaf area diseased, and death of leaves were noted. The procedure was repeated three times weekly from budbreak to harvest for a total of 396 disease assessments corresponding to 45, 44, and 43 observations in 2016, 2017, and 2018, respectively, for each of the three plots (Vidal and Vandal-Cliche with natural wetness and Vandal-Cliche with artificial wetness). Disease assessment on the five fully expanded youngest leaves was used in all analysis. Daily, the duration of leaf wetness (h) and mean temperature $\left({ }^{\circ} \mathrm{C}\right)$ during leaf wetness were used as input variables in the infection model developed from controlled experiments to calculate daily RSEV values. When leaf wetness was interrupted by $2 \mathrm{~h}$ or less, it was considered as continuous; however, the duration of dryness and temperature during this period was not considered when calculating the total duration of wetness (Magarey et al. 1993). These values of RSEV were compared with anthracnose severity, expressed as PLAD on 1- to 7day-old leaves, assessed 7 days later. The 396 paired data (observed and predicted disease severity) were split into two data sets. One data set, including two-thirds of the data (264 observations), was used to validate the controlled experiments model, and the remaining data (132 observations) were used to validate the reliability of the risk chart. Separately for each plot and chronemically, every three observations, two and one observations, randomly selected, were used for model and risk chart validation, respectively. The predictive capacity of the model was assessed by performing a simple regression analysis between the observed disease severity and the predicted RSEV as paired observations. Based on the study by Carisse and MorissetteThomas (2013), three levels of anthracnose severity were used to construct the risk chart, with light, moderate, and severe risk of disease corresponding to $\leq 5,>5$ to $\leq 25$, and $>25 \%$ leaf area diseased, respectively. The reliability of the risk chart was assessed by constructing a contingency table including the proportions of 132 observations correctly classified as mild, intermediate, or severe. The classification was done using the predicted RSEV using duration of leaf wetness and temperature during the wetness period as input in the model developed from controlled experiments. The resulting predicted RSEV was corrected to account for the relationship between controlled and vineyard anthracnose severity (model validation step).

\section{Results}

Influence of temperature and duration of leaf wetness under controlled conditions. Based on an $F$ test, there was no significant difference in percent germination of the E. ampelina conidia (89 to $95 \%)$ used as inoculum for inoculation $(P=0.36)$. Regardless of the assay or the temperature, no lesions developed on leaves not exposed to postinoculation wetness (Fig. 1). At $5^{\circ} \mathrm{C}$ during the infection, few lesions developed when vines were exposed to $24 \mathrm{~h}$ of 
leaf wetness, with less than $1 \%$ disease severity. At $10^{\circ} \mathrm{C}$ during the infection, few lesions developed at wetness durations of 2 to $6 \mathrm{~h}$, which increased to 5.97 and $17.94 \%$ leaf area diseased after 12 and $24 \mathrm{~h}$ of leaf wetness, respectively (Fig. 1). The response of disease severity to leaf wetness duration was similar at temperatures of 15 , 20,25 , and $30^{\circ} \mathrm{C}$ during the infection, with low disease severity at leaf wetness durations shorter than 4 to $6 \mathrm{~h}$ and rapid increase

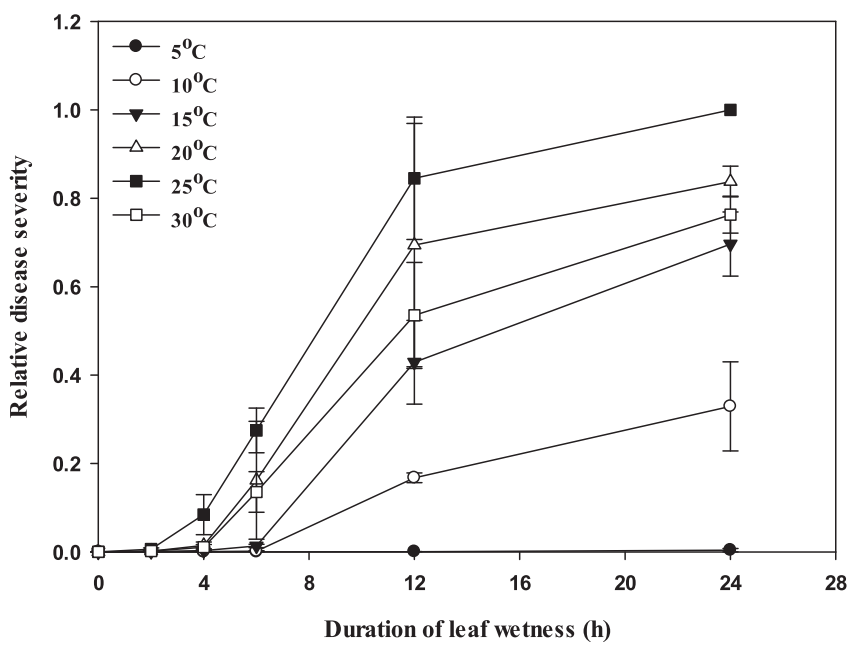

Fig. 1. Relative disease severity caused by Elsinoë ampelina on grape exposed during the infection period to various temperatures and leaf wetness durations. Values are the average of 90 observations (three assays $\times$ two shoots per plant $\times$ three plants $\times$ five leaves per plant), and the bars represent the standard error.

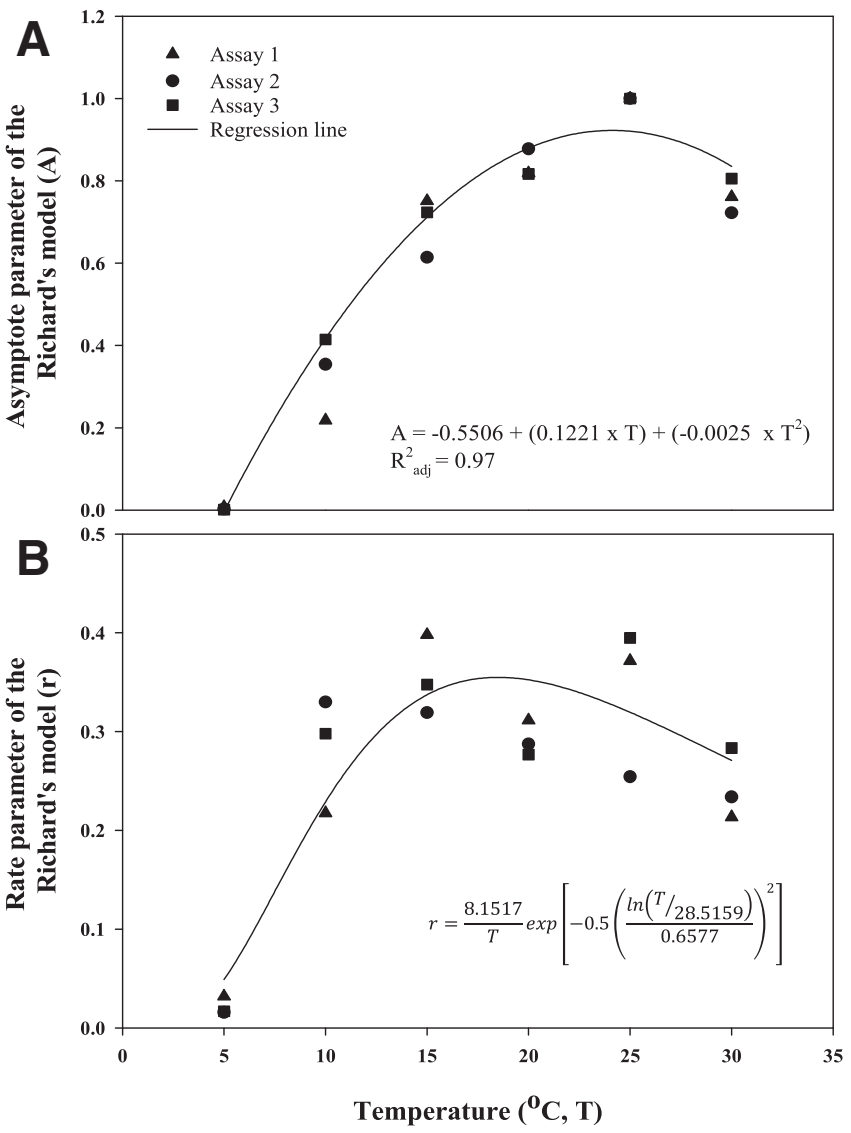

Fig. 2. Response of $\mathbf{A}$, the upper asymptote (parameter $A$ in equation 1 ) and $\mathbf{B}$, the rate (parameter $r$ in equation 1 ) as a function of temperature. The line represents the predicted value calculated from equations 4 and 5 , respectively, and the symbols represent the observed values for each experimental repetition (assay). between leaf wetness durations of 6 and $12 \mathrm{~h}$, followed by smaller increases between 12 and $24 \mathrm{~h}$ of leaf wetness (Fig. 1). After $6 \mathrm{~h}$ of leaf wetness, the mean disease severities were $0.71,8.68,21.78$, and $7.30 \%$ at $15,20,25$, and $30^{\circ} \mathrm{C}$, respectively, during the infection. After $12 \mathrm{~h}$ of leaf wetness, the mean disease severities were 22.73 , $37.74,44.83$, and $28.78 \%$ at $15,20,25$, and $30^{\circ} \mathrm{C}$, respectively, during the infection. After $24 \mathrm{~h}$ of leaf wetness, the mean disease severities were $40.46,45.44,46.36$, and $35.65 \%$ at $15,20,25$, and $30^{\circ} \mathrm{C}$, respectively, during the infection. Based on observed anthracnose severity, the optimum temperature for infection of grape leaves by $E$. ampelina was $25.0^{\circ} \mathrm{C}$. The minimum duration of leaf wetness required for infection was $4 \mathrm{~h}$ at $25^{\circ} \mathrm{C}$ and $6 \mathrm{~h}$ at temperatures below or above $25^{\circ} \mathrm{C}$ (Fig. 1).

Model development. The upper asymptote (parameter $A$ ) of the Richards model was 0 at $5^{\circ} \mathrm{C}$ and increased gradually to reach the maximum of 1.0 at $25^{\circ} \mathrm{C}$, after which it declined to 0.76 at $30^{\circ} \mathrm{C}$ (Fig. 2A). The response of the upper asymptote to temperature was best described by the following equation (Fig. 2A):

$$
A=-0.5506+(0.1221 \times T)+\left(-0.0025 \times T^{2}\right)
$$

where $A$ is the asymptote parameter of the Richards model (equation 1) and $T$ is the temperature in ${ }^{\circ} \mathrm{C}$. Using the mean value for the $m$ parameter in equation 1, which was 1.0553 (minimum of 1.0005 and maximum of 1.1447), the model that best described (smallest sum of square) the rate parameter $(r)$ of the Richards model (equation 1 ) as a function of temperature was:

$$
r=\frac{8.1517}{T} \exp \left[-0.5\left(\frac{\ln (T / 28.5159)}{0.6577}\right)^{2}\right]
$$

where $r$ is the rate parameter and $T$ is the temperature in ${ }^{\circ} \mathrm{C}$ (Fig. 2B). The surface response model was obtained by integrating equation 4 , which represents the response of the asymptote to temperature, the shape parameter $m=1.0553$, and by integrating equation 5 , which represents the response of the rate parameter to temperature. The final equation was:

$$
R D S=A *\left[1-\exp ^{-r w}\right]^{\frac{1}{(1-1.0553)}}
$$

where $R D S$ is the RSEV, $A$ is the asymptote (equation 4 ), $r$ is the rate of disease progress (equation 5), and $w$ is the duration of leaf wetness (h) (Fig. 3). The model accurately predicted RSEV from leaf wetness

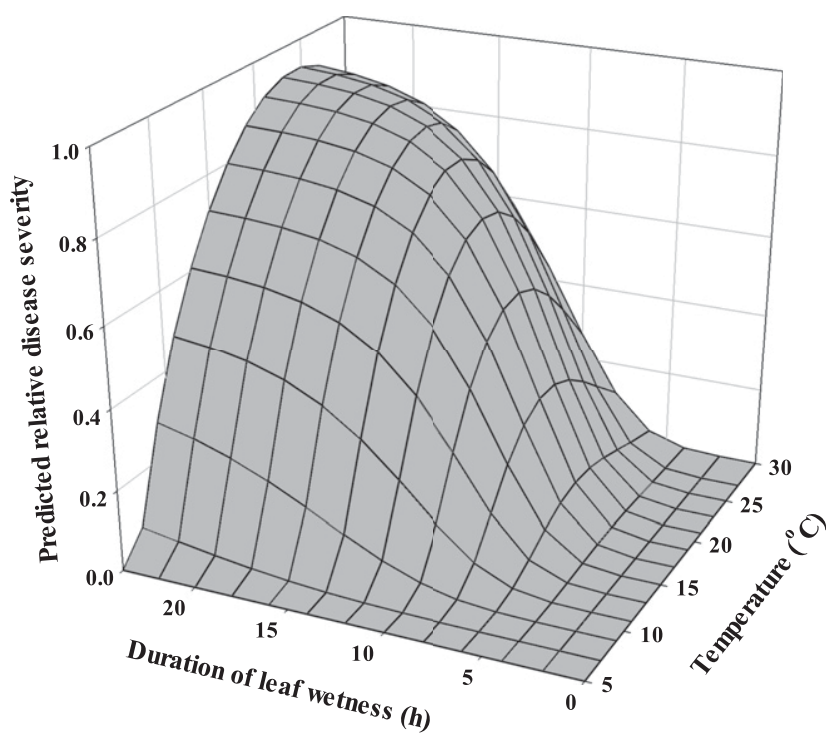

Fig. 3. Three-dimensional response of relative disease severity caused by Elsinoë ampelina on grape leaves to the combined effects of temperature and leaf wetness duration. The predicted values were calculated using equation 6 (described in the text). 
duration and temperature during the wetness period with a coefficient of determination, $\mathrm{CCC}$, and $\mathrm{Cb}$ of $0.94,0.89$, and 0.92 , respectively (Fig. 4). Inspection of residual plots revealed a random pattern of distribution for all temperatures and leaf wetness durations. The intercept of the regression of the observed RSEV against predicted RSEV was equal to 0.0191 , which was not significantly different from $0(P=0.2041)$, with a slope of 1.0645 , which was not significantly different from $1(P=0.9457)$. Based on the prediction model, the optimum conditions for infection of grape leaves by $E$. ampelina are $24 \mathrm{~h}$ of leaf wetness at $24.5^{\circ} \mathrm{C}$ (Fig. 3).

Validation of the infection model and development of a risk chart. The predictive capacity of the infection model was assessed using vineyard data collected in vineyard plots planted with the grape varieties Vidal and Vandal-Cliche and subjected to natural and artificial leaf wetness. In total, 22, 27, and 26 leaf wetness events were analyzed in plots exposed to natural wetness and 32, 30, and 29 leaf wetness events were analyzed in the plot exposed to artificial wetness in 2006, 2007, and 2008, respectively. For each leaf wetness event (leaf wetness $>2 \mathrm{~h}$ ), the risk of infection using the previously described model (equation 6) calculated with the leaf wetness duration and temperature during the wetness period was compared with disease severity assessed 7 days later. There was a linear relationship between observed disease severity expressed as PLAD and predicted RSEV (Fig. 5). The intercept of the regression of the observed disease severity against predicted RSEV was equal to 1.0680 , which was not significantly different from $0(P=5190)$, with a slope of 1.1536 , which was significantly greater than different from $1(P=0.005)$ (Fig. 5), indicating that the model tended to overestimate disease severity. As both observed disease severity and RSEV increased, the departure from the concordance line increased (Fig. 5). The contingency table made from the risk calculated from equation 6 and corrected for the linear relationship between controlled and vineyard disease severity as risk $=1.0680+(1.1536 \times \mathrm{RSEV})$ showed that, for the 132 observations, 83,17 , and 32 observations were classified as mild, intermediate, and severe risk, respectively. Overall, $93.9 \%$ of observations were correctly classified, with $100,29.4$, and $9.4 \%$ of the mild, intermediate, and severe risks, respectively.

\section{Discussion}

In Quebec, the first epidemics of anthracnose occurred on VandalCliche (Carisse and Lefebvre 2011a). In recent years, however, there have been several outbreaks reported on Vidal, a hybrid grape variety, and on some of the newer cold-hardy varieties that are gaining in popularity such as Marquette, which are highly susceptible, or Frontenac and La Crescent, which are moderately susceptible (Carisse and Lefebvre 2011b). In the context of northern viticulture, grape varieties such as Vidal and Marquette play an important role as lead varieties for ice wine and red wine, respectively. Thus, these varieties are there to stay, and cost-effective anthracnose management strategies must be developed. Also, there is an increasing demand for wine that is organic or produced in an environmentally friendly manner, which is extremely difficult for varieties susceptible to anthracnose. Thus, understanding the factors that trigger the development of anthracnose epidemics is essential in order to design and implement effective management strategies. This has motivated the initiation of this study addressing the effects of leaf wetness duration and temperature during wetness periods on infection of grape leaves by $E$. ampelina.

The first experiment was conducted under controlled conditions and consisted of studying the influence of a range of constant temperatures ( 5 to $30^{\circ} \mathrm{C}$ ) and continuous leaf wetness durations ( 0 to $24 \mathrm{~h}$ ) on anthracnose severity expressed as PLAD. Regardless of the temperature tested, no disease developed when grapevines were not exposed to leaf wetness, which means that tissue wetness is essential for infection.

Regardless of leaf wetness duration, no disease developed at $5^{\circ} \mathrm{C}$, and the minimum leaf wetness durations were $2 \mathrm{~h}$ at $25^{\circ} \mathrm{C}, 4 \mathrm{~h}$ at 20 and $30^{\circ} \mathrm{C}$, and $6 \mathrm{~h}$ at 10 and $15^{\circ} \mathrm{C}$ (Fig. 1). At all temperatures except $5^{\circ} \mathrm{C}$, PLAD gradually increased with increasing leaf wetness duration, reaching a maximum level at a leaf wetness duration of $24 \mathrm{~h}$. These results are not fully in agreement with some published results of studies examining the influence of temperature and tissue wetness on anthracnose infection. It was reported in previous studies that infection of grapevine tissue occurs at temperatures ranging from 2 to $40^{\circ} \mathrm{C}$, with an optimum temperature ranging between 30 and $35^{\circ} \mathrm{C}$ (Mirica 1988; Suhag and Grover 1977). In this study, we were not able to test temperatures above $30^{\circ} \mathrm{C}$. However the optimum temperature for infection was around $25^{\circ} \mathrm{C}$, above which the PLAD decreased. Regarding leaf wetness duration, previous work by Brook (1973) and Magarey et al. (1993) suggested that severe infection occurs after $1.5 \mathrm{~h}$ of tissue wetness at $30^{\circ} \mathrm{C}, 3$ to $4 \mathrm{~h}$ at $21^{\circ} \mathrm{C}, 4$ to $7 \mathrm{~h}$ at $16.5^{\circ} \mathrm{C}$, and 7 to $10 \mathrm{~h}$ at $12^{\circ} \mathrm{C}$, which is in agreement with the results of our study. The results of this study and of previous ones clearly show that E. ampelina requires relatively short tissue wetness durations under a wide range of temperatures to cause severe infection (Brook 1973; Magarey et al. 1993; Mirica 1988; Suhag and Grover 1977; Virk and Grover 1979).

When RSEV derived from the model developed under controlled experiments (equation 6) was validated using vineyard data, there was a linear relationship between predicted and observed disease severity. However, the relationship was not a 1-to-1 relationship (perfect concordance between predicted and observed values) (Fig. 5). This can be explained by the same inoculum concentration, constant

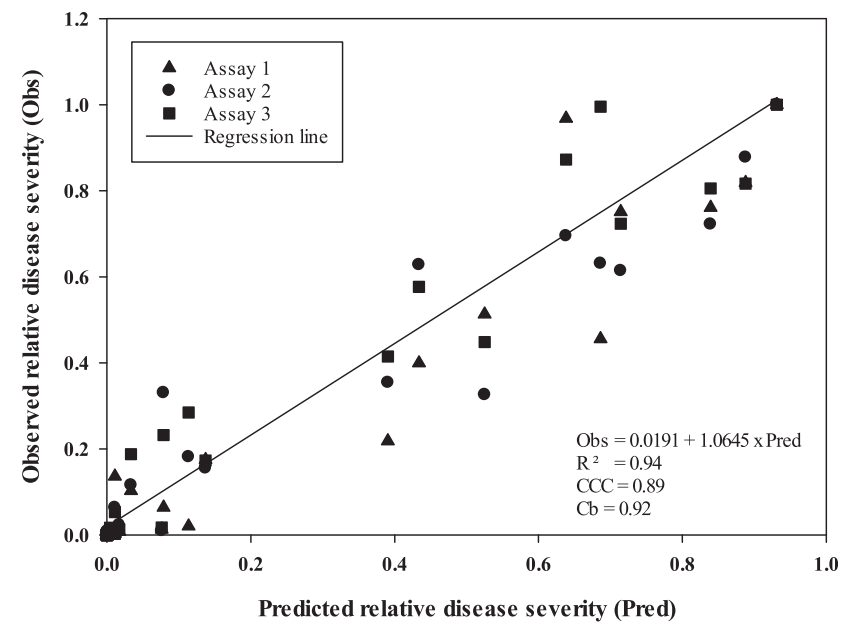

Fig. 4. Regression of observed relative disease severity (RSEV) against predicted RSEV calculated using equation 6 for grape anthracnose caused by Elsinoë ampelina under controlled conditions. CCC = concordance correlation coefficient and $\mathrm{Cb}=$ bias coefficient.

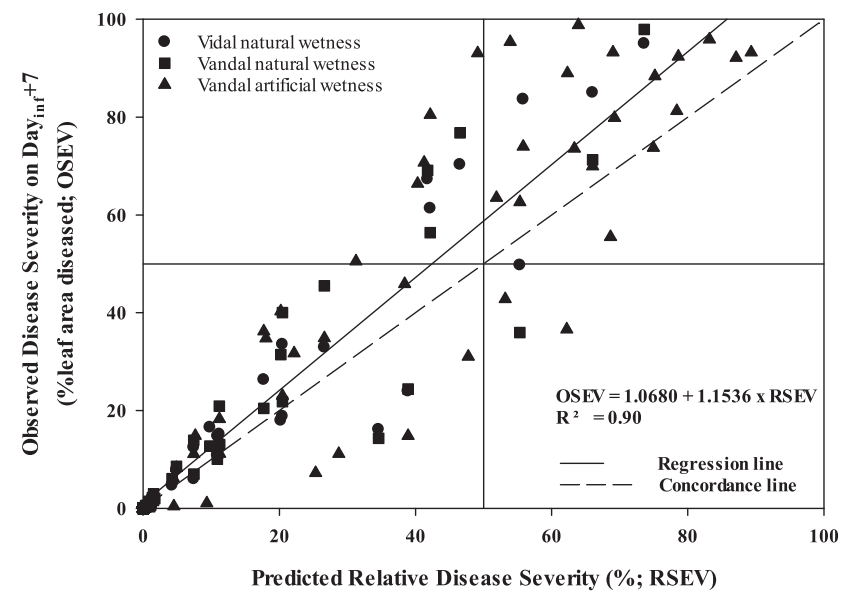

Fig. 5. Relationship between observed disease severity on grape leaves under vineyard conditions against predicted relative disease severity calculated using equation 6 . Full and dashed lines represent the regression (observed against predicted) and concordance lines (perfect prediction), respectively. 


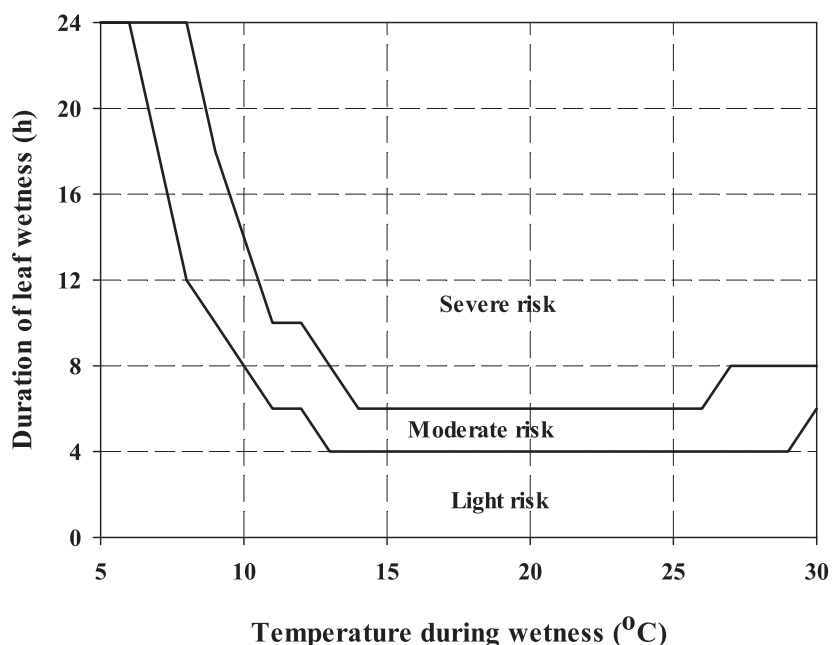

Fig. 6. Grapevine anthracnose risk chart for infection of leaves by Elsinoë ampelina. Categories are based on the response surface generated using equation 6 and corrected for the linear relationship between controlled and vineyard disease severity as risk $=1.0680+(1.1536 \times \mathrm{RSEV})$. Isopleths separating the categories indicate light risk, corresponding to relative disease severity (RSEV) between 0 and $5 \%$; moderate risk, corresponding to RSEV $>5 \%$ and $<25 \%$; and severe risk, corresponding to RSEV $>25 \%$ leaf area diseased.

temperature, and continuous leaf wetness used during the controlled experiment, as opposed to fluctuating inoculum concentrations and temperatures and sometimes interrupted leaf wetness. Also, leaf wetness was monitored using two sensors, and it is expected that there were variations in duration of leaf wetness at the scale of the vineyard plots. Also, the departure of the regression line from the concordance line (perfect prediction) increased as anthracnose severity increased (Fig. 5). This might be explained by an increasing inoculum concentration over time due to the polycyclic nature of grape anthracnose (Carisse and Lefebvre 2011a).

In their study, Carisse and Morissette-Thomas (2013) studied the influence of host and weather factors on grapevine defoliation caused by E. ampelina. They reported that, based on their study, the most important factors influencing grapevine defoliation are rain frequency and duration, leaf age, and proportion of leaf area diseased at the time of infection. The results suggest that, in order to avoid premature leaf drop, disease severity should be maintained below $25 \%$ leaf area diseased. Hence in this study, 25\% leaf area diseased was used as the threshold for severe risk of anthracnose, and $\leq 5$ and $>5$ to $\leq 25 \%$ were used as thresholds for light and moderate risk of anthracnose, respectively. Considering that, at temperatures from 5 to $30^{\circ} \mathrm{C}$, only a few hours of leaf wetness is required to cause infection (Fig. 1), the interval of leaf wetness duration for intermediate risk was quite narrow (Fig. 6). It is important to note that, in this study, anthracnose was assessed only on young leaves approximately 1 to 10 days old, which are probably more receptive to infection than older ones (Carisse and Morissette-Thomas 2013). Nevertheless, the model and risk chart developed in this study can be used with forecast weather to time fungicide application in both conventional and organic production. However, to fully understand grape anthracnose and to design cost-effective management strategies, more research is needed. Research should be directed toward understanding the relationship between anthracnose severity and crop losses, disease development on berries, overwintering, and ontogenic resistance. To improve management, more information is needed on fungicide efficiency, synthetic fungicides, and fungicide effectiveness and resistance.

\section{Acknowledgments}

We thank A. Lefebvre and D. Rolland for their technical assistance.

\section{Literature Cited}

Barros, L. B., Biasi, L. A., Carisse, O., and May De Mio, L. L. 2015. Incidence of grape anthracnose on different Vitis labrusca and hybrid cultivars and rootstocks combination under humid subtropical climate. Australas. Plant Pathol. 44:397-403.

Brook, P. J. 1973. Epidemiology of grapevine anthracnose, caused by Elsinoe ampelina. N. Z. J. Agric. Res. 16:333-342.

Brook, P. J. 1992. Epidemiology of grapevine anthracnose and downy mildew in Auckland, New Zealand vineyard. N. Z. J. Crop Hortic. Sci. 20:37-49.

Carisse, O., Bacon, R., Lasnier, J., Lefebvre, A., Levasseur, A., Rolland, D., and Jobin, T. 2009. Grape disease management in Quebec. Agriculture and Agri Food Canada publication number 10372E, catalogue number A52-146/ 2009E-PDF. https://www.agrireseau.net/petitsfruits/documents/Grape $\% 20$ disease $\% 20$ management $\% 20$ in \%20Quebec.pdf

Carisse, O., and Kushalappa, A. C. 1990. Development of an infection model for Cercospora carotae on carrots based on temperature and leaf wetness duration. Phytopathology 80:1233-1238.

Carisse, O., and Lefebvre, A. 2011a. A model to estimate the amount of primary inoculum of Elsinoë ampelina. Plant Dis. 95:1167-1171.

Carisse, O., and Lefebvre, A. 2011b. Evaluation of northern grape hybrid cultivars for their susceptibility to anthracnose caused by Elsinoë ampelina. Plant Health Prog. 12. https://apsjournals.apsnet.org/doi/10.1094/PHP-20110805-01-RS

Carisse, O., and Morissette-Thomas, V. 2013. Epidemiology of grape anthracnose: Factors associated with defoliation of grape leaves infected by Elsinö ampelina. Plant Dis. 97:222-230.

Du Plessis, S. J. 1940. Anthracnose of vines and its control in South Africa. Department of Agriculture, South Africa, Sci. Bull. No. 216.

Hopkins, D. L., and Harris, J. W. 2000. A greenhouse method for screening grapevine seedlings for resistance to anthracnose. HortScience 35:89-91.

Madden, L. V., Hughes, G., and van den Bosch, F. 2007. The Study of Plant Disease Epidemics. American Phytopathological Society, St. Paul, MN, U.S.A

Magarey, R. D., Coffey, B. E., and Emmett, R. W. 1993. Anthracnose of grapevines, a review. Plant Prot. Q. 8:106-110.

Mirica, I. I. 1988. Anthracnose. Pages 18-19 in: Compendium of Grape Diseases. R. C. Pearson and A. C. Goheen, eds. American Phytopathological Society, St. Paul, MN, U.S.A.

Plocher, T. A., and Parke, R. J. 2001. Northern Winework: Growing Grapes and Making Wine in Cold Climates. Northern Winework Inc., Hugo, MN, U.S.A.

Shear, C. L. 1929. The life history of Sphaceloma ampelinum de Bary. Phytopathology 19:673-679.

Suhag, L. S., and Grover, R. K. 1972. Overwintering and control of Elsinoe ampelina, the cause of grapevine anthracnose. Pages 294-299 in: Viticulture in the Tropics. K. Chadha, G. Randhowa, and R. Pal, eds. Horticultural Society of India, New Delhi, India.

Suhag, L. S., and Grover, R. K. 1977. Epidemiology of grapevine anthracnose caused by Sphaceloma ampelinum in north India. Indian Phytopathol. 35: 526-528.

Thind, S. K., Arora, J. K., Nirmaljitkour, P. K., and Arora, P. K. 2001. Periodicity and prediction model of grape anthracnose in Punjab: An agrometeorological approach. Plant Dis. Res. 16:63-67.

Virk, K., and Grover, R. 1979. Effect of thiophanate-methyl on growth and metabolic activity of Sphaceloma ampelinum. Indian Phytopathol. 32:529-533. 